\title{
CHINY
}

\section{Karolina Mazurowska}

\section{EFEKTYWNA WSPÓŁPRACA Z CHIŃCZYKAMI Z PERSPEKTYWY MIĘDZYKULTUROWEJ PSYCHOLOGII BIZNESU}

We współczesnym globalizującym się świecie kontakty międzykulturowe i współpraca z partnerami z zagranicy stały się codziennością. W ostatnich latach coraz więcej Polaków podejmuje współpracę z Chińczykami, ale również wiele chińskich firm otworzyło w Polsce swoje oddziały. Na rodzimym rynku coraz bardziej widoczne są takie korporacje chińskie jak Huawei, Haier czy Lenovo. Obecność chińskich pracowników w Polsce stwarza okazję do zacieśnienia wymiany gospodarczej z Państwem Środka, z którym jest ona niezbalansowana. Jednocześnie niesie obu stronom zaangażowanym w kooperację problemy dotyczące różnic kulturowych w podejściu do pracy.

\section{Globalne firmy uczq̨ się pracy na rynku chińskim na własnych błędach}

Nowoczesne technologie umożliwiają współdziałanie firm położonych w odległych względem siebie miejscach, ale też w przestrzeni wirtualnej, może zatem niektórym się wydawać, że tam właśnie formy komunikacji i interakcji zunifikowały się i upodobniły do wzorców zachodnich. Nic bardziej mylnego. Nawet międzynarodowe platformy internetowe czy firmy e-commerce, aby efektywnie działać, muszą dostosować swoje praktyki do wymogów lokalnego rynku i odmiennego kulturowo klienta. Jak pokazuje przykład Airbnb, platformy internetowej do wynajmu mieszkań w pobliżu atrakcji turystycznych, jej strategia wejścia na rynek chiński nie była w wystarczającym stopniu dostosowana do potrzeb lokalnych odbiorców. Po 
pierwsze, zmieniono nazwę firmy na Aibiying (爱彼迎 $)^{1}$, którą chińscy internauci odebrali negatywnie i uznali za źle brzmiącą. Choć założyciel i dyrektor generalny Airbnb Brian Chesky oznajmił, że nowa nazwa oznacza ,powitanie z miłością”, to nie spotkało się to z przyjaznym odzewem ${ }^{2}$. Po drugie, portal ma na rynku chińskim lokalną konkurencję - firmę Tujia o wiele większym zasięgu i liczbie oferowanych miejsc. Po trzecie, firma Airbnb do tej pory nie brała pod uwagę specyfiki kulturowej klientów. Chińczycy bowiem lubią podróżować kolektywnie, a więc w ofercie powinny się znaleźć mieszkania na tyle duże, by nadawały się do wynajmu przez grupę - rodzinę czy znajomych. Strategię firmy powoli więc dostosowuje się do chińskiego klienta (Airbnb oferuje między innymi bezpłatne wycieczki jako dodatek do wynajętego miejsca, chińskojęzyczny serwis 24/7 oraz możliwości opłaty poprzez Alipay czy Wechat pay), ale dzięki starannemu zbadaniu rynku pod względem kulturowym oraz znajomości lokalnych norm i zwyczajów można było od razu uniknąć sytuacji, która nadszarpnęła wizerunek firmy.

\section{Trudności w kontaktach międzykulturowych}

W międzykulturowym środowisku skuteczna współpraca jest szczególnie trudna ze względu na nieznajomość norm i wartości kultur partnerów. U osób wchodzących ze sobą w kontakt międzykulturowy zwiększa się poziom niepokoju (czynnik emocjonalny) oraz niepewności (czynnik poznawczy). W konsekwencji są one przyczyną większej trudności w komunikacji interkulturowej w porównaniu $\mathrm{z}$ intrakulturową, odbywającą się w jednej kulturze $\mathrm{e}^{3}$. Co więcej, przeszkodą w efektywnej pracy jest etnocentryzm, będący ,pierwotnym rozwojowo stanem umysłu, który uniemożliwia złożone widzenie rzeczywistości międzykulturowej i satys-

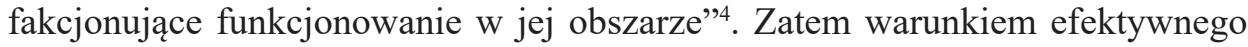
działania na przestrzeni kultur jest otwartość poznawcza, postawa etnorelatywna, a więc taka, w której istnieje świadomość różnic kulturowych oraz chęć spojrzenia na zachowanie partnera z perspektywy jego kultury i zrozumienia zależności jego

${ }^{1}$ Opis przypadku w artykule Airbnb's New Chinese Name Panned by Netizens, portal Shanghaiist http://shanghaiist.com/2017/03/22/airbnb-becomes-aibiying.php [dostęp 22 marca 2017].

2 Airbnb Makes China Push with Local Name Change, ,Financial Times”, https://www.ft.com/ content/1e5bacc2-0e98-11e7-b030-768954394623 [dostęp 22 marca 2017].

${ }^{3}$ Karolina Mazurowska, Paweł Boski, Czynniki istotne $w$ procesie rozwiazywania konfliktu $w$ międzykulturowym środowisku pracy. Triangulacja w interpretacji danych, „Psychologia Społeczna" 2014, t. 9, nr 1 (28), s. 38-54.

${ }^{4}$ Więcej na temat koncepcji etnocentryzmu-etnorelatywizmu w: P. Boski, Kulturowe ramy zachowań społecznych. Podręcznik psychologii międzykulturowej, Wydawnictwo Naukowe PWN, Academica Wydawnictwo SWPS, Warszawa 2009, rozdz. 14, s. 566-573. 
postępowania. Osiągnięcie jej jest dla wielu wyzwaniem, ponieważ, jak zauważa Milton Bennett, „wrażliwość kulturowa nie jest stanem »naturalnym« wśród ludzi, zatem przezwyciężenie go jest kwestią »rozwoju w sprzyjających warunkach lub treningu «"s. Automatyczne stosowanie rozwiązań zaczerpniętych z jednej kultury grozi tym, że zostaną one zupełnie inaczej zinterpretowane niż w kulturze, z której pochodzą. Na przykład pytania chińskich pracowników wobec niemieckiego szefa z zagranicy dotyczą osobistych spraw i mają na celu zbudowanie dobrej relacji, przez niego zaś są niekiedy interpretowane jako pogwałcenie normy rozdzielającej życie prywatne od pracy zawodowej ${ }^{6}$.

Sytuacja kontaktu międzykulturowego jest zatem niezwykle złożona i choć trudno znaleźć uniwersalne wskazówki dla partnerów biznesowych, można mówić o pewnych zasadach w podejściu do współpracy. Richard R. Gesteland zaproponował ogólne wytyczne dotyczące funkcjonowania w biznesie międzynarodowym. Po pierwsze, można oczekiwać, że usługodawca dostosuje się do usługobiorcy, a sprzedawca do nabywcy, ale także przybysz będzie przestrzegał miejscowych zwyczajów?

Polscy importerzy oczekują często, że to chińscy producenci dostosują się bardziej do kultury klienta. Niestety rzeczywistość wygląda nieco inaczej. Niektórzy badacze kultury chińskiej uważają, że Chińczycy poznawczo i emocjonalnie oddzielili modernizację od westernizacji. Pielęgnując swoje specyficzne kulturowo sposoby zachowania, są jednocześnie w stanie przyjąć zachodnie praktyki i osiągać sukces w nowoczesnych firmach bez utraty chińskiej tożsamości ${ }^{8}$. Co więcej, analizy Frances Brew i Davida R. Cairnsa wskazały, że to zachodni menedżerowie, pochodzący zwykle z kultur indywidualistycznych, dopasowywali się stylem komunikacji do lokalnych współpracowników (z kultury kolektywistycznej), wybierając mniej bezpośrednią strategię komunikacji ${ }^{9}$. Badania pokazują, że większe wyzwanie związane z rozpoznawaniem niepewnych sytuacji i dobraniem

5 Tamże, s. 567.

${ }_{6}^{6}$ Tego rodzaju przykłady współpracy zostały zebrane przez autorkę w badaniach własnych podsumowanych w artykule K. Mazurowska, P. Boski, Czynniki istotne...

7 Richard R. Gesteland, Różnice kulturowe a zachowania w biznesie. Marketing negocjacje i zarzadzanie w różnych kulturach, przekł. Hanna Malarecka-Simbierowicz, Wydawnictwo Naukowe PWN, Warszawa 2000.

8 Jamie Littrell (2002), Desirable Leadership Behaviors of Multicultural Managers in China, http://romielittrellpubs.homestead.com/files/littrell_2002.pdf, 2002, za: Michael H. Bond, Ambrose Y.C. King, The Confucial Paradigm of Man. A Sociological View, w: Wen-Shing Tseng, David Y.H. Wu (red.), Chinese Culture and Mental Health, Academic Press, Orlando 1985, s. 29-45.

9 Frances P. Brew, David R. Cairns, Does Culture or Situational Constraints Determine Choice of Direct or Indirect Styles of Intercultural Workplace Conflicts?, „International Journal of Intercultural Relations" 2004, nr 28, s. 331-352. 
efektywnej metody komunikacji leży po stronie obcokrajowca-ekspatrianta (expata), będącego w Azji gościem.

W przypadku polskich firm eksportujących na rynek chiński znajomość lokalnej kultury może mieć o wiele większe znaczenie w powodzeniu biznesu niż ograniczenie się tylko do znajomości etykiety i formalności na oficjalnych spotkaniach. Chiny są najszybciej rosnącym rynkiem konsumentów, także na rynku e-commerce, z coraz większą konkurencją firm globalnych oraz lokalnych walczących o klienta. Dlatego aby rozwój strategii marketingowej, brandingu i komunikacji z klientem był skuteczny, musi być dostosowany do lokalnej kultury. Należy wziąć pod uwagę fakt, że chiński rynek cechuje coraz większa innowacyjność firm lokalnych ${ }^{10}$ (jak Alibaba ${ }^{11}$, Tencent) oraz zaawansowane metody płatności (Alipay, Wechat pay). Co więcej, chińscy konsumenci są coraz lepiej wykształceni, poinformowani i obyci z międzynarodowymi markami. W firmie nastawionej na eksport do Chin konieczne zatem staje się rozwijanie umiejętności skutecznego funkcjonowania na tamtym rynku, a grupa osób, które powinny posługiwać się aktualną wiedzą kulturową, obejmuje różne działy firmy (marketing, produkcję itp.). Znajomość kultury firmy importującej znacznie obniża ryzyko niepowodzenia we wprowadzaniu nowych produktów. Przykładem może być jeden z większych polskich eksporterów pieluch dla dzieci, który nie wziął pod uwagę znacznie mniejszych rozmiarów swoich małych chińskich klientów, co skutkowało załamaniem sprzedaży ze względu na niedopasowanie produktu do jego odbiorcy.

\section{Różnice kulturowe istołne w prowadzeniu efektywnej działalności handlowej}

W badaniach psychologii międzykulturowej dokonano kategoryzacji kultur pod kątem wartości wyznawanych przez jej członków. Powstało wiele pogłębionych projektów badawczych na skalę międzynarodową - między innymi badania

${ }^{10}$ Shaun Rein, The End of Copycat China. The Rise of Creativity, Innovation and Individualism in Asia, John Wiley and Sons Inc., Hoboken, New Jersey 2014. Patrz także Georges Haour, Max von Zedtwitz, Created in China. How China is Becoming a Global Innovator, Bloomsbury Information, London 2016; George S. Yip, Bruce Kern, China's Next Strategic Advantage. From Imitation to Innovation, MIT Press, Cambridge Mass., London 2016.

${ }^{11}$ Chiński portal sprzedażowy Alibaba oferuje małym i średnim przedsiębiorstwom alternatywne rozwiązanie, którym jest sprzedaż internetowa i przesyłka zamówionych produktów z dowolnego państwa świata. Portal opiera się na modelu biznesowym B2B (business to business) ułatwiającym współpracę między producentami oraz dystrybutorami. Alibaba.com oferuje firmom założenie wirtualnego sklepu, w którym zostanie przedstawiona niezbędna informacja o marce, oferowanym produkcie oraz producencie, a potencjalnym nabywcom umożliwia bezpośredni kontakt z firmą itd. 
Geerta Hofstedego ${ }^{12}$, projekt GLOBE ${ }^{13}$, Shaloma H. Schwartza ${ }^{14}$, projekt Trompenaarsa i Hampden-Turnera ${ }^{15}$ - które wskazują umiejscowienie poszczególnych kultur narodowych na konkretnych wymiarach w odniesieniu do pracy zawodowej. Spośród wielu podejść do porównywania kultur zostaną wybrane i opisane na podstawie badań te, których znajomość może szczególnie wpłynąć na poprawę efektywności w pracy z Chińczykami.

\section{Odmienności w podejściu do współpracy biznesowej}

Różnice w podejściu do współpracy biznesowej przedstawione poniżej zostały oparte na najbardziej aktualnym, międzykulturowym i obszernym projekcie z zakresu psychologii organizacji i zarządzania - GLOBE. Kultura społeczeństwa, organizacji oraz style przywódcze 61 krajów zostały przedstawione w dziewięciu wymiarach, które częściowo można znaleźć we wcześniejszych badaniach nad międzykulturowym zarządzaniem Hofstedego: dystans władzy, unikanie niepewności, asertywność, kolektywizm instytucjonalny, kolektywizm grupowy, orientacja przyszłościowa, równość płci, orientacja humanistyczna, orientacja na wykonanie. Powyższe wymiary zbadano w projekcie GLOBE pod kątem praktyk (as it is - tak jak to jest w rzeczywistości) oraz wartości (as it should be - tak jak powinno być) uznawanych w danym społeczeństwie. Przedstawione dane dotyczą porównania polskiej, niemieckiej i chińskiej kultury zarządzania ${ }^{16}$.

Wymiar dystans władzy mówi o tym, na ile dane społeczeństwo akceptuje fakt, że siła i władza w organizacjach społecznych jest rozłożona nierówno. W procesie

${ }^{12}$ Geert Hofstede, Culture's Consequences. International Differences in Work Related Values, Sage, Beverly Hills 1980; tenże, Kultury i organizacje: zaprogramowanie umystu, przekł. Małgorzata Durska, Polskie Wydawnictwo Ekonomiczne, Warszawa 2000, 2007 (wyd. 1 i 2).

${ }_{13}$ Robert House, Paul J. Hanges, Mansour Javidan, Peter W. Dorfman, Vipin Gupta, Leadership, Culture and Organizations. The GLOBE Study of 62 Societies, Sage, Thousand Oaks CA 2004.

${ }^{14}$ Shalom H. Schwartz, Universals in the Content and Structure of Values. Theoretical Advances and Empirical Tests in 20 Countries, „Advances in Experimental and Social Psychology” 1992, nr 25, s. 1-65.

${ }^{15}$ Fons Trompenaars, Charles Hampden-Turner, Siedem wymiarów kultury. Znaczenie róznic kulturowych $w$ działalności gospodarczej, przekł. Bogumiła Nawrot, Oficyna Ekonomiczna, Kraków 2002.

${ }^{16}$ Pingping Fu, Rongxian Wu, Yongkang Yang, Yun Je, Chinese Culture and Leadership, w: Jagdeep S. Chhokar, Felix C. Brodbeck, Robert J. House, Culture and Leadership Across the World the GLOBE Book of In-Depth Studies of 25 Societies, 2012, s. 877-909. Dane do chińskiej części projektu zbierano w Szanghaju, największym przemysłowym mieście Chin, zajmującym strategiczną pozycję w Państwie Środka na próbie 158 menedżerów średniego szczebla pracujących w przemyśle spożywczym i w branży finansowej. 
socjalizacji Chińczyków uczono akceptacji dla hierarchii w ramach pięciu wertykalnych relacji (wu lun, 五伦), których należało przestrzegać w odniesieniu do innych członków społeczeństwa, czyli relacji pomiędzy władcą a poddanym, ojcem i synem, mężem a żoną, starszym a młodszym bratem, starszym a młodszym przyjacielem ${ }^{17}$. Poziom dystansu władzy jest najniższy w Niemczech, w Chinach i w Polsce zaś kształtuje się podobnie. W kulturze chińskiej wysoki wynik rzeczywisty (as it is) wskazuje na wysoką tolerancję dla nierówności, natomiast wynik dla idealnego stanu wskazuje na to, że preferują oni bardziej egalitarny stosunek do hierarchii we współczesnym społeczeństwie ${ }^{18}$. Ping Ping Fu, jeden $\mathrm{z}$ autorów chińskiej analizy w projekcie GLOBE, jest zdania, że wpływy kultury zachodniej są widoczne wśród młodszej generacji Chińczyków w ich potrzebie zachowania równości we władzy (equality of power), ale także w zachowaniach pogwałcających tradycyjne normy, takie jak absolutny szacunek i posłuszeństwo wobec starszych $^{19}$. Philip Murtaugh, prezes General Motors China, mówi: „Moje frustracje powstają wtedy, gdy zatrudniam mądrych ludzi po politechnice Qinghua czy uniwersytecie Jiaotong [dwie najlepsze chińskie uczelnie], a oni podchodzą do twojego biurka i mówią: »Za trzy lata chcę mieć twoją pracę«. Zajęło mi 25 lat życia, aby zajść tak wysoko. Trzeba nauczyć się tego biznesu, nie zrobi się tego w trzy lata" ${ }^{20}$. Dystans władzy w środowisku pracy w Chinach oznacza także, że pracownicy niechętnie dyskutują z decyzjami podjętymi przez przełożonych. Jest to problem we współpracy z Chińczykami i aby ją usprawnić, zachodni menedżerowie optują za przekazywaniem prerogatyw na niższy poziom w hierarchii oraz za zagęszczeniem struktury w chińskim oddziale firmy ${ }^{21}$. W hierarchicznych społeczeństwach Azji Wschodniej, szczególnie zaś w Chinach, groźba utraty wizerunku tworzy potrzebę unikania sytuacji, w których zaangażowane osoby odczuwałyby zażenowanie, co skutkuje omijaniem tematów problematycznych ${ }^{22}$. Dlatego osoba współpracująca z Chińczykami powinna dużo częściej kontaktować się z nimi, aby trzymać rękę na pulsie i próbować wysondować, czy sprawy toczą się w dobrym kierunku. Wymaga to od zachodniego menedżera dużo większej pracy, ale i wrażliwości na informacje niewypowiedziane wprost, lecz niewątpliwie komunikowane.

Hierarchia odgrywa również dużą rolę w negocjacjach biznesowych. Odkrycie, kto jest osobą, która de facto podejmuje decyzje po chińskiej stronie, stanowi dla

${ }^{17}$ Fan Ying, A Classification of Chinese Culture, „Cross Cultural Management” 2000, nr 7 (2) s. $3-10$.

${ }^{18} \mathrm{Fu}$ i in., Chinese..., s. 891.

19 Tamże.

20 Juan Antonio Fernandez, Laurie Underwood, China CEO Voices of Experience from 20 International Business Leaders, John Wiley \& Sons (Asia) Pte Ltd., Singapore 2006.

${ }^{21}$ Tamże, s. 55.

22 J.A. Fernandez, L. Underwood, China CEO... 
partnera spoza Chin wyzwanie ze względu na to, że w kulturach kolektywistycznych w negocjacjach często bierze udział tak zwana surogatka lidera, a nie właściwy decydent ${ }^{23}$. Dla odmiany w Niemczech, gdzie dystans władzy jest niski ${ }^{24}$, ludzie generalnie uważają innych za równych sobie, a hierarchia zakłada nierówność ról, nie zaś nierówność pomiędzy jednostkami. W negocjacjach w kulturach indywidualistycznych bierze udział lider mający prerogatywy do podejmowania decyzji, nawet jeśli nie jest szefem firmy ${ }^{25}$. Zatem zidentyfikowanie właściwego interlokutora w chińskim zespole może znacząco przyśpieszyć efektywność działań.

Unikanie niepewności określa stopień, w którym jednostki poszukują porządku, stałości, struktury oraz formalnych procedur, aby poradzić sobie z sytuacjami życia codziennego. To także silna emocjonalna potrzeba ujmowania wszystkiego w ramy przepisów i praw, aby nie dopuścić do niepewnych sytuacji w życiu społecznym ${ }^{26}$. Chińczycy są w ogólnym rankingu na dziesiątym miejscu, co stanowi dość wysoki wynik w tym wymiarze, Niemcy osiągają piąty najwyższy wynik, relatywnie niskie wyniki charakteryzują Polaków, którzy w mniejszym stopniu odczuwają potrzebę unikania niepewności ${ }^{27}$. Wprawdzie warunki życia w Chinach zdecydowanie się poprawiły w ostatnich dziesięcioleciach, to jednak pewna część społeczeństwa nie radzi sobie z przemianami społecznymi, co rodzi sentyment za dawnymi czasami ,żelaznej miski ryżu”, ale i potrzebę odnoszenia się do praw i odgórnie wydawanych regulacji, a co za tym idzie - biurokracji. Współcześnie istniejący wysoki poziom unikania niepewności oznacza, że Chińczycy wolą, żeby ich życie było ustrukturyzowane, dobrze zorganizowane, a dzięki temu bezpieczne. Obowiązki i kompetencje każdego pracownika, a także podział pracy są ściśle wyznaczone. Przepływ informacji wśród pracowników jest sformalizowany, metody rozwiązywania problemów zaś wcześniej wytyczone i spisane w regulaminach, przepisach i ustawach. Bardzo wysoki stopień zbiurokratyzowania nastręcza współpracownikom europejskim wiele problemów ze względu na to, że decyzje w firmie muszą przejść wiele szczebli w hierarchii, zanim zostaną ogłoszone. Niechęć niższych rangą pracowników do samodzielnego podejmowania decyzji powoduje niekiedy frustrację partnerów z Europy. Jednym z rozwiązań jest zachęcenie współpracowników do bardziej samodzielnych działań, choć nie jest to łatwy proces, o czym mówi menedżer z Lenovo Group: „Taka sytuacja jest dla mnie bezpieczna. Ja mam pracę i mój szef ma pracę. Jeśli dasz mi możliwość podejmowania decyzji, a ja

${ }^{23} \mathrm{Z}$ ang. leader's surrogate. Więcej na temat zespołów negocjacyjnych w kulturach kolektywistycznych i indywidualistycznych Iris Verner, Linda Beamer (red.), Intercultural Communication in the Global Workplace, McGrow-Hill, New York 2011, rozdz. 9: Intercultural Negotiation Teams.

${ }^{24}$ R. House i in., Leadership, Culture and Organizations...

${ }^{25}$ I. Verner, L. Beamer (red.), Intercultural...

${ }^{26} \mathrm{Fu}$ i in., Chinese..., s. 891.

${ }^{27}$ R. House i in., Leadership, Culture and Organizations... 
zrobię błąd, to ja będę temu winien. Chińczycy nie lubią ponosić winy. Możemy odpowiadać za pracę, którą wykonujemy, ale zwykle nie chcemy mieć tej możliwości podejmowania się czegoś nowego, ze względu na strach przed porażką. Jakkolwiek [uważam, że] powinniśmy to robić częściej w Chinach"28.

Wymiar kolektywizm instytucjonalny podkreśla rolę lojalności grupowej, zbiorowych interesów pewnych grup i wzajemnej odpowiedzialności członków społeczeństwa. Chińskie społeczeństwo jest nadal bardzo kolektywistyczne, co odzwierciedla wynik na skali praktyk (as it is) - 7 na 61 państw. W przeciwieństwie do tego niemieckie i polskie społeczeństwo jest bardzo indywidualistyczne. W przypadku tego wymiaru zmiany w Chinach postępują bardzo szybko, szczególnie zaś w środowisku biznesu międzynarodowego. Tradycyjnie hierarchiczne ustawienie pracowników w firmie zostaje powoli zastąpione bardziej egalitarnym podejściem do nich, szczególnie przez zachodnich pracodawców. Nagradzane są także indywidualne inicjatywy, które wcześniej były tępione jako akt wywyższania się i egoizmu. Z wymiarem tym łączy się inny, określany jako kolektywizm grupowy, który podkreśla lojalność grupową, poczucie dumy z przynależności do różnego jej typu - począwszy od rodziny przez krąg przyjaciół po jednostkę w pracy - oraz istotność działań podejmowanych na rzecz wspólnych interesów ${ }^{29}$. Chińczycy wypadają w tej skali bardzo wysoko - miejsce dziewiąte w ramach praktyk (as it is). Ten wynik nie jest zaskakujący, ze względu na wagę, jaką Chińczycy zawsze przykładali do rodziny, altruizmu, lojalności i cnoty xiao (chin. 孝, ang. filial piety) - zobowiązań wobec rodziców i szefów w pracy przy jednoczesnym piętnowaniu indywidualnych przedsięwzięć. Współczesna praktyka odzwierciedla wpływ tradycyjnych wartości, które ostatnio jednak mieszają się z zachodnimi, podkreślającymi większy indywidualizm. W celu osiągnięcia lepszej pozycji w firmie lub/i większych pieniędzy młodzi ludzie decydują się na częste zmiany miejsca pracy - tiaocao (跳槽), co wskazuje na zmniejszającą się lojalność wobec jednego pracodawcy ${ }^{30}$. Według niedawnego badania przeprowadzonego przez instytut badawczy Mycos Chińczycy urodzeni po 1990 r., którzy ukończyli studia w 2011 r., byli zatrudniani przez średnio dwóch różnych pracodawców w ciągu trzech lat. Badanie wykazało też, że w ciągu trzech lat $8 \%$ z nich zatrudnia się w czterech lub więcej miejscach pracy. Tylko $38 \%$ absolwentów pracowało w tej

${ }^{28}$ Frank T. Gallo, Business Leadership in China. How to Blend Best Western Practices with Chinese Wisdom, John Wiley \& Sons (Asia) Pte Ltd., Singapore 2008, s. 100.

${ }^{29} \mathrm{Fu}$ i in., Chinese..., s. 891.

${ }^{30}$ Więcej na temat przyczyn tego zjawiska w Chinach np. w China's Post-90s Workers: The Job-Hopping Generation, http://www.whatsonweibo.com/chinas-post-1990s-job-hopping-generation/ [dostęp 20 maja 2017]; czy też w artykule przytaczającym statystyki: Zhaopin: Nearly 80\% of China White Collars Trying to Switch Jobs, http://zhaopin.investorroom.com/2017-02-28-Zhaopin-Nearly-80-of-China-White-Collars-Trying-to-Switch-Jobs [dostęp 25 maja 2017]. 
samej firmie przez całe trzy lata ${ }^{31}$. Stanowi to wyzwanie dla firm zachodnich, które posługują się rozmaitymi metodami w celu zbudowania lojalności chińskiego pracownika. Ma on bowiem wysokie wymagania wobec pracodawcy czy partnera z zagranicy, o czym mówi jeden z polskich przedsiębiorców cytowanych w broszurze wydanej dla biznesu: „Po szkoleniach, w które zainwestowaliśmy mnóstwo środków, traciliśmy to, co było naszym największym majątkiem, czyli wykwalifikowanych pracowników. Byliśmy zdumieni i zdziwieni, że odchodzą. Dopiero po jakimś czasie zdaliśmy sobie sprawę, że traktowanie miejsca pracy także jako domu jest o wiele ważniejsze [...], a szczególnie ważne jest utrzymywanie atmosfery dobrych i pozytywnych relacji pomiędzy pracownikami. W momencie kiedy te relacje zostały zaburzone, pracownicy uważali, że złamało się kręgosłup zespołu i mimo że otrzymali znacznie więcej niż u innych pracodawców, odchodzili" ${ }^{32}$.

Współpracę w biznesie z Chińczykami można usprawnić poprzez większe zrozumienie odmiennego poczucia czasu. Orientacja na przyszłość w projekcie GLOBE określa, na ile pożądane w społeczeństwie jest planowanie w długiej perspektywie czasowej, sekwencyjne wykonywanie zadań i odraczanie gratyfikacji. W zakresie praktyk Chiny są w środku skali (34. na 61 państw), Niemcy są na miejscu 13., Polska zaś ma jeden z najniższych wyników w orientacji przyszłościowej wśród krajów biorących udział w projekcie. Kultura chińska do niedawna była jeszcze kulturą wiejską, w której planowanie długofalowe wiązało się z cyklem upraw. Oznaczało to konieczność oszczędzania na czas nieurodzaju; oszczędność uznawano za cnotę. Z perspektywy taoistów należało zdać się na los i na naturalną kolej rzeczy, planowanie było zatem niepotrzebne i wbrew naturze ${ }^{33}$. Ma to znaczenie w biznesie ze względu na to, że Chińczycy są zorientowani na długoterminową kooperację i jednorazowe korzyści nie są celem ich współpracy ${ }^{34}$. „Wiele polskich projektów skończyło się w Chinach z powodów odmiennych perspektyw czasowych, często wielkich nadziei i oczekiwań polskiej strony, jakże często niemożliwych do zrealizowania w krótkim czasie", pisze autor jednej z broszur przeznaczonych

31 Post-90s generation czy Jiǔ líng hòu (90-after, 九零後) - tym terminem określa się pokolenie Chińczyków, szczególnie tych zamieszkałych w miastach, którzy urodzili się między 1990 a 2000 r. Jest to pokolenie urodzone po erze Mao (1976) i protestach na placu Tiananmen (1989), a także podlegające polityce jednego dziecka (1978), patrz więcej Manya Koetse, China’s Post-90s Workers: The Job-Hopping Generation, wrzesień 2016, http:/www.whatsonweibo.com/chinas-post-1990s-job-hopping-generation/ [dostęp 6 czerwca 2017].

32 Radosław Pyffel (współpraca Centrum Współpracy Gospodarczej Polska-Chiny, PAIiIZ), Biznes w Chinach - jak uniknąć problemów, Warszawa 2013, s. 16, http://www.gochina.gov.pl/files/?id plik=224 [dostęp 20 maja 2017].

${ }_{33}$ G. Hofstede, Culture's Consequences...

${ }^{34}$ Ang. long-term orientation to termin wprowadzony przez Geerta Hofstedego do badań nad kulturą organizacyjną; patrz analiza w odniesieniu do Chin https:/geert-hofstede.com/china.html [dostęp 20 maja 2017]. 
dla polskich przedsiębiorców w Chinach ${ }^{35}$. Polacy mają problem z patrzeniem w perspektywie pięciu czy dziesięciu lat - dopiero pokazanie chińskiemu partnerowi perspektywy współpracy i dalekosiężnego planu oraz własnej cierpliwości i wytrwałości daje szansę powodzenia ${ }^{36}$. W Chinach kolejne możliwości biznesowe są szczegółowo analizowane i drobiazgowo oceniane przed podjęciem właściwej decyzji. W krajach zachodnich, na przykład w Niemczech, uznaje się, że okazja do współpracy biznesowej powinna być wykorzystana, jeśli tylko się pojawi ${ }^{37}$. Chińska koncepcja czasu ma skutki dla sytuacji konfliktowych, a w negocjacjach szczególnie, jako że chińscy pracownicy mają inne podejście do nagłości spraw (different conceptions of urgency) $)^{38}$, tempa i sekwencji wykonywanych czynności w czasie. Zachodni partnerzy handlowi często odczuwają zmieszanie, frustrację czy wręcz złość, obserwując i doświadczając chińskiego podejścia do procedur, terminów i potrzeby negocjowania wielu spraw w tym samym czasie ${ }^{39}$. W Chinach godzina 12.00 - pora lunchu - jest przyczyną frustracji wielu polskich biznesmenów, którym wydaje się, że tracą czas, idąc z lokalnymi współpracownikami na posiłek. W chińskich realiach jest to jednak mile widziane i oczekiwane, przyjętą bowiem normą jest kontynuowanie rozmów biznesowych na mniej oficjalnym gruncie restauracji, w której można lepiej poznać partnera, wypytać go o życie prywatne, wymienić się nieformalnymi informacjami o statusie współpracy i zacieśnić relacje osobiste. W kulturze, w której orientacja humanistyczna ${ }^{40}$ charakteryzuje się wysokim wskaźnikiem, jakość relacji współpracujących osób staje się kluczowa, a wręcz determinuje sposoby rozwiązywania nieuniknionego konfliktu ${ }^{41}$.

35 R. Pyffel, Biznes w Chinach..., s. 17.

36 Tamże.

${ }^{37}$ Felix C. Brodbeck, Michael Frese, Societal Culture and Leadership in Germany, w: J.S. Chhokar, F.C. Brodbeck, R.J. House, Culture and Leadership..., s. 147-215.

${ }^{38}$ Lucian W. Pye, Chinese Commercial Negotiating Style, Rand Corporation, Santa Monica CA. 1982.

${ }^{39}$ Paul S. Kirkbride, Sara F. Tang, Robert I. Westwood, Chinese Conflict Preferences and Negotiating Behavior. Cultural and Psychological Influences, „Organization Studies” 1991, nr 12 (3), s. 365-386. Więcej na ten temat: Zhi Xue Zhang, Jianjun Zhang (red.), Understanding Chinese Firms from Multiple Perspectives, Springer, Peking University Press, Berlin, Peking 2014.

${ }^{40}$ Orientacja humanistyczna rozumiana jest w projekcie GLOBE jako stopień, w jakim jednostki należące do danej społeczności są wspierane we wszelkich zachowaniach, których celem jest udzielenie innym pomocy, bycie sprawiedliwym, altruistycznym, opiekuńczym, wybaczającym czy po prostu milym dla innych.

${ }^{41}$ J.A. Fernandez, L. Underwood, China CEO..., s. 29. 


\section{Tradycyinie chińskie cechy kulturowe wpływajq̨ce na efektywność współpracy biznesowej w Chinach ${ }^{42}$}

W komunikacji międzykulturowej istotne znaczenie ma używanie wysokiego lub niskiego kontekstu wypowiedzi ${ }^{43}$. W kulturach niskiego kontekstu kładzie się nacisk na bezpośredniość, zwięzłość komunikatu, na konieczność umieszczenia znaczenia w słowach ${ }^{44}$. Kontakty z osobami, których kultury pochodzenia charakteryzują się niskim kontekstem, wymagają od partnerów biznesowych „nazywania rzeczy po imieniu", natomiast w kulturze wysokiego kontekstu, w tym w chińskiej, istotna jest komunikacja niebezpośrednia, ponieważ znaczenie ulokowane jest w kontekście. Współpraca z nimi wymaga zatem „znacznie bardziej rozbudowanego przekazu oraz zachowania określonych rytuałów komunikowania, takich jak ceremoniał, szacunek dla partnera" ${ }^{45}$. Słowo wypowiedziane w kulturach wysokokontekstowych nie jest najważniejszym środkiem przekazu; zakłada się tam, że rozmówca będzie potrafił domyślić się wielu ważnych kwestii, które są istotą rozmowy, należy zatem umieć czytać między wierszami. W takich kulturach częste jest implikowanie znaczenia, a także ekspresja niewerbalna zgodnie z formuła yizai yan wai (意在言外) - „prawdziwe znaczenie ukryte jest poza słowami”

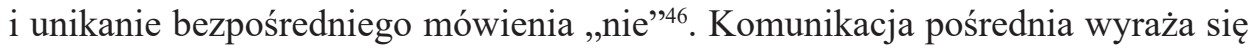
w formułach: you xie wenti (有些问题) - ,są z tym pewne problemy”, bu fangbian (不方便) - ,to nie do końca nam pasuje”, women yanjiu yanjiu -(我们研究研究) - „przemyślimy to”, czy wo bu tai qinchu (我不太清楚) - „nie do końca wiem” jako sposób uniknięcia odmowy. Dla zachodnich menedżerów efektywna, a więc bezpośrednia komunikacja jest bardzo ważna, ponieważ wpływa na umiejętność zarządzania, wypracowywania wyników i osiągania sukcesu w międzynarodowej korporacji ${ }^{47}$. Jedna $\mathrm{z}$ badanych niemieckich menedżerek tak opisuje to zjawisko:

I wyjaśniam projekt, i generalnie daję im wskazówki, co mają robić i oni siedzą tam i słuchają ciebie i mówią „tak, rozumiemy”. Mówisz

${ }^{42} \mathrm{~W}$ międzykulturowej psychologii biznesu określa się je jako indygeniczne (ang. indigenous) - wytworzone przez lokalne warunki kulturowe. Zob. m.in. Uichol Kim, Kuo-shu Yang, Kwang-Kuo Hwang (red.), Indigenous and Cultural Psychology. Understanding People in Context, Springer, Berlin 2006.

${ }^{43}$ Edward T. Hall, Beyond Culture, Doubleday, New York 1976.

${ }^{44}$ Thomas M. Holtgraves, Styles of Language Use. Individual and Cultural Variability in Conversational Indirectness, „,Journal of Personality and Social Psychology” 1997, nr 73, s. 624-637.

${ }^{45}$ Małgorzata Budzanowska-Drzewiecka, Aleksander S. Marcinkowski, Agata Motyl-Adamczyk, Różnice kulturowe w komunikacji biznesowej, Wydawnictwo Uniwersytetu Jagiellońskiego, Kraków 2016, s. 55.

${ }^{46}$ Ge Gao, Stella Ting-Toomey, Communicating Effectively with the Chinese, Sage, Thousand Oaks CA 1998, rozdz.1: Self-other Perspective and Communication, s. 1-19.

${ }^{47}$ K. Mazurowska, P. Boski, Czynniki istotne w procesie... 
im, co mają robić, na czym się skupić, ale mówią, że rozumieją, i pytasz jeszcze raz i jeszcze raz, a oni mówią ,,jesteśmy pewni”, więc wracają do pracy i wracają do ciebie po jakimś czasie, w którym mieli wykonać ten projekt i oczywiście to nie odnosi się do tego, co mówiłaś, co wyjaśniałaś, w tej sytuacji patrzą na ciebie, a ty myślisz „czy ja wam nie mówiłam, czego dotyczy ten projekt?" [...]. I czytasz w tej pracy, którą dostarczyli, i to nie jest to, co było wcześniej omawiane.

Chińscy pracownicy mają trudności z wyraźnym powiedzeniem „nie”, co więcej, potrzebują większego pokierowania nimi i wyjaśnienia im w szczegółach, o co chodzi w danym zadaniu ${ }^{48}$. W Polsce czy w Niemczech, gdyby współpracownik nie był pewien, co ma zrobić, to wróciłby po dalsze wskazówki, po feedback, zanim zacząłby pracę - Chińczycy zwykle tego nie robią. Rozwiązaniem jest częste egzekwowanie wyników w pracy, dawanie krótszego deadlinu oraz dopytywanie się, jak współpracownik zrozumiał nasz komunikat, z prośbą o parafrazę, raczej niż pytania, czy w ogóle komunikat zrozumia ${ }^{49}$.

W chińskim środowisku pracy nadrzędną rolę wobec efektywności w komunikacji odgrywają ustawienie hierarchiczne oraz normy grzeczności. Kolejna badana Chinka współpracująca z niemieckimi firmami w Pekinie mówi w wywiadzie: $\mathrm{Z}$ niemieckim szefem byłabym taka, byłabym bardziej bezpośrednia, ale to był Chińczyk, więc mogłam mu powiedzieć, co się dzieje [w firmie], ale mu nie powiedziałam" 50 . Chińczycy są tak keqi (客气) ${ }^{51}$ - uprzejmi w swoim zachowaniu, szczególnie gdy nie chcą urazić szefa czy partnera z zagranicy - że dochodzi niekiedy do zablokowania przepływu informacji na temat tego, co się dzieje na przy$\mathrm{kład} \mathrm{z} \mathrm{bieżącym} \mathrm{projektem.} \mathrm{W} \mathrm{efekcie} \mathrm{zachodni} \mathrm{menedżer} \mathrm{może} \mathrm{czekać} \mathrm{na} \mathrm{rezul-}$ tat wykonanej pracy, podczas gdy pracownik chiński nie miał śmiałości przyjść do niego po feedback ${ }^{52}$.

Mówiąc o komunikacji, nie można nie wspomnieć o chińskiej etykietalności zachowania przejawiającej się w odpowiednim przedstawieniu siebie i firmy, wymianie grzeczności i prezentów, wspólnych lunchach i kolacjach budujących zaufanie itp. Parę lat temu do dobrego tonu należało posiadanie wizytówek w języku

${ }^{48}$ Cytaty pochodzą z badań autorki przeprowadzonych w międzynarodowych korporacjach w Chinach: K. Mazurowska, Kulturowe i osobowościowe czynniki warunkujace harmonijne lub konfliktowe zachowania organizacyjne. Chinczycy i Europejczycy w międzykulturowym środowisku pracy, praca doktorska, Szkoła Wyższa Psychologii Społecznej, Warszawa 2011.

49 Tamże.

50 Tamże.

${ }^{51}$ Ge Gao, S. Ting-Toomey, Communicating Effectively..., rozdz. 3: Charakteristics of Chinese Communication - Keqi, s. 45.

52 J.A. Fernandez, L. Underwood, China CEO... 
chińskim i przedstawianie się partnerom chińskim poprzez zapośredniczony kontakt. Obecnie sytuacja się zmieniła dzięki powszechnemu użyciu aplikacji Wechat (Weixin) ${ }^{53}$, z której korzysta ponad $830 \mathrm{mln}$ Chińczyków ${ }^{54}$. Jest to medium łączące cechy Facebooka, WhatsAppa i innych komunikatorów pozwalających na nagrywanie krótkich wiadomości dźwiękowych i odsłuchiwanie ich w dowolnej chwili. Wechat stał się ostatnio popularnym narzędziem komunikacji między firmami, w których te same osoby z obu stron, wcześniej zaznajomione, rozwijają relacje poprzez przesyłanie sobie wiadomości na Wechat, zarówno prywatnych, jak i firmowych. Jest to więc nieoficjalny kanał komunikacji, dzięki któremu można omówić pewne sprawy służbowe niejako w kuluarach, zanim zostaną oficjalnie przekazane drogą mailową. Dzięki Wechatowi komunikacja między firmami może się stać dużo efektywniejsza, Chińczycy bowiem znacznie częściej odbierają wiadomości Wechat niż wiadomości przesyłane e-mailem. Chińscy partnerzy chętnie więc zeskanują kod QR, łącząc się tym samym z nowym kooperantem zaraz przy pierwszym spotkaniu.

W kulturze chińskiej istnieją jeszcze dwa indygeniczne konstrukty psychologiczne, które mogą się przyczynić do zwiększenia efektywności współpracy. Są to koncepcja przysługi, która wiąże się z bao (报) - odwzajemnianiem się, oraz guanxi (关系) - sieci społecznych relacji. W codziennym dyskursie często występują wyrażające wdzięczność i konieczność spłacenia długu powiedzenia: gan en tu bao (感恩图报) - „odczuwać wdzięczność za czyjeś uprzejme zachowanie i planować odpłacić się za to”, gan en dai de (感恩戴德) - „nieść ciężar wdzięczności za czyjąś uprzejmość" 55 czy chengyu - Li shang wang lai (礼尚往来) - „odwzajemniać pozdrowienia, przysługi i prezenty”. Przysługi wyświadczone na rzecz innych Chińczycy uznają za swego rodzaju inwestycje, które druga strona w relacji powinna wynagrodzićs ${ }^{5}$. Jeśli ktoś nie odpłacił za prezenty lub przysługi, Chińczycy mówią, że bu dong renqing (不懂人情) - (on) nie rozumie pozytywnych emocji między ludźmi. Dlatego odwzajemnienie się prezentami podczas spotkań biznesowych należy do normatywnych zachowań w kulturze chińskiej i jest oczekiwane przez partnera współpracującego z Azjatami.

W kulturze chińskiej guanxi (关系) odnosi się do szczególnego rodzaju nieformalnych, osobistych związków międzyludzkich opartych na wzajemnych

${ }^{53}$ G.S. Yip, B. Kern China's Next...

${ }^{54}$ Zob. na temat częstotliwości użytkowania aplikacji Wechat w Chinach China Digital Landscape Transformation, Bowen Li dla TEDXHult Shanghai, https:/www.youtube.com/watch?v=wjRySkvEN9w [dostęp 20 maja 2017].

${ }_{55}$ Ge Gao, S. Ting-Toomey, Communicating Effectively..., rozdz. 2: Chinese Personal Development Process, s. 29.

${ }_{56}$ Kuo-shu Yang, Indigenous Personality Research. The Chinese Case, w: Uichol Kim i in. (red.) Indigenous and Cultural..., s. 285-314. 
zobowiązaniach i różni się ono pod wieloma względami od sieci społecznych relacji pomiędzy ludźmi w kulturze zachodniej. Koncepcja guanxi była już wielokrotnie opisywana ${ }^{57}$, jest ona jednak ważna w kontekście usprawnienia współpracy z Chińczykami. Wierzą oni bowiem, że dostęp do właściwych kontaktów społecznych może być zdecydowanie bardziej efektywny w dążeniu do osiągnięcia upragnionych celów niż czynności podejmowane na własną rękę ${ }^{58}$. Zaproszenie na przykład do restauracji osoby, z którą chce się zawrzeć guanxi, oraz spędzenie czasu w atmosferze bliskości, jeżeli przebiega stopniowo, tworzy zaufanie, a to wstęp do nawiązania długotrwałych relacji biznesowych. Zachodni przedsiębiorcy nie czują się komfortowo z akceptowaniem prezentów, dla Chińczyków zaś jest to codzienna praktyka kulturowa. „Mieliśmy jednego klienta, który był z nami związany dziesięć lat. Uważaliśmy, że należy wręczyć mu jakiś mały prezent. Ale [niemiecki] szef powiedział, że to nie jest konieczne", tak wypowiedziała się chińska menedżerka niższego szczebla pracująca w niemieckiej firmie handlowej w Pekinie ${ }^{59}$. W Chinach pielęgnowanie relacji z długoterminowym klientem odbywa się poprzez wręczanie mu upominków, czego często nie biorą pod uwagę zagraniczni inwestorzy, nie przeznaczając w firmowych budżetach stosownych środków na ten cel.

Podobnie do guanxi znajomość chińskiej koncepcji zachowania twarzy liu mian$z i$ (留面子) może mieć znaczący wpływ na współpracę. Partnerzy zachodni mają tendencję do postrzegania sytuacji biznesowych w kategoriach dobra-zła, prawdy-fałszu, podczas gdy chińska tradycja jest bardziej skoncentrowana na kwestii ,twarzy" niż na wiarygodności jednostki. Michael H. Bond argumentował, że ochrona czyjejś twarzy jest istotniejsza niż obiektywna prawda ${ }^{60}$. Zaleca się jednak zagranicznym inwestorom na rynku chińskim ostrożność w bezwarunkowym przestrzeganiu tradycyjnych praktyk ocalenia twarzy, ze względu na podwójne standardy zachowań stosowane przez chińskich kontrahentów ${ }^{61}$. Jak argumentuje Jarek Lin-

${ }^{57}$ Por. m.in. Si Qin Peng, Guanxi - Management and Legal Approaches to Establish and Enhance Interpersonal Trust, ,Journal of Psychology in Chinese Societies” 2001, nr 2 (1), s. 51-76; Thomas Gold, David Guthrie, Daniel Wank, Social Connections in China-Institutions, Culture and the Changing Nature of Guanxi, Cambridge University Press, Cambridge 2002; Eike A. Langenberg, Guanxi and Business Strategy Theory and Implications for Multinational Companies in China, Springer, Berlin 2007; czy literatura wydana w Polsce: Ewa Zajdler (red.) Zrozumieć Chińczyków. Kulturowe kody spoleczności chińskich, Wydawnictwo Akademickie Dialog, Warszawa 2011; Yan Wang, Wpływ modernizacji Chin na funkcjonowanie guanxi w chińskim społeczeństwie, „Azja-Pacyfik” 2015, t. 18.

${ }^{58}$ YinLun So, Anthony Walker, Explaining Guanxi. Chinese Business Network, Routledge, Newy York 2013.

${ }^{59}$ K. Mazurowska, Kulturowe...

${ }^{60}$ M.H. Bond, Beyond Chinese Face, Oxford University Press, Hong Kong 1991.

${ }^{61}$ Jarek Linka, Rola twarzy w chińskim marketingu relacji-opinie polskich menadżerów pracujacych w Chinach, w: Grażyna Rosa, Agnieszka Smalec, Marketing przyszłości. Trendy. Strategie. Instrumenty. Zachowania nabywców wczoraj, dziś i jutro, „Zeszyty Naukowe” nr 594, „Ekonomiczne 
ka, który przeprowadził wiele wywiadów z polskimi inwestorami w Chinach, dawanie twarzy i jej ochrona są praktykowane w fazie wzajemnego poznawania się partnerów biznesowych, po tym etapie zaś następuje przejście do fazy negocjacji i analizowania kwestii merytorycznych. Należy więc rozdzielić fazę wstępną w budowaniu relacji (artykułowaną poprzez zachowanie ceremonialności) od właściwej fazy współpracy, w której bardziej bezpośrednie komunikowanie propozycji i oczekiwań zwiększa efektywność w biznesie z Chińczykami ${ }^{62}$.

Wykres 1. Średnie dla kultur niemieckiej, chińskiej oraz polskiej dla praktyk (PR) badanych w projekcie GLOBE ${ }^{63}$

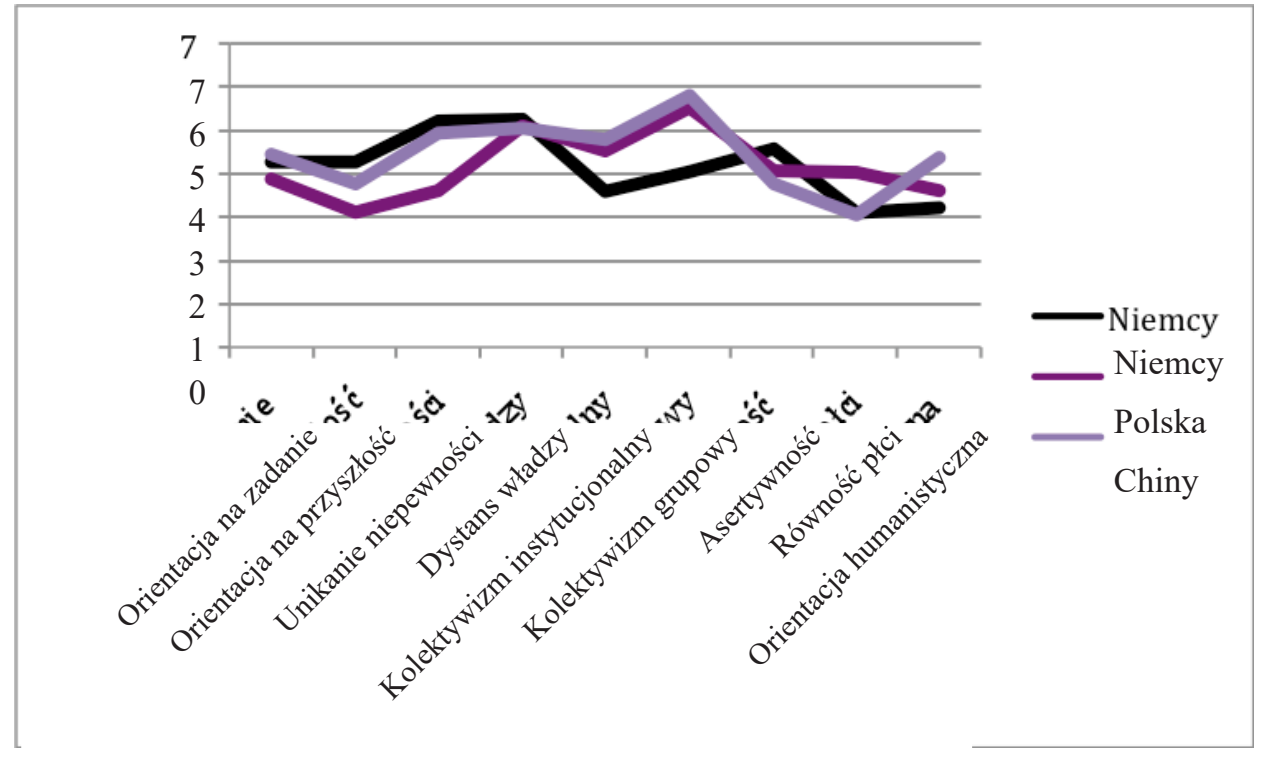

Podsumowanie powyższej analizy przedstawia wykres. W zakresie praktyk w ramach orientacji na zadanie spośród trzech branych pod uwagę państw Chiny osiągają najwyższy wynik, a Polska najniższy. Polska ma także najniższy wynik w orientacji przyszłościowej ze wszystkich 61 krajów biorących udział w projekcie. W zestawieniu trzech państw Chiny osiągają w tym wymiarze najwyższą średnią. W skali unikanie niepewności Niemcy osiągają piąty, najwyższy wynik, Chińczycy są w ogólnym rankingu na dziesiątym miejscu, a relatywnie niskie wyniki

Problemy Usług” nr 54, Wydawnictwo Naukowe Uniwersytetu Szczecińskiego, Szczecin 2010, s. 341-352.

${ }^{62}$ Tamże, s. 352.

${ }^{63}$ K. Mazurowska, Kulturowe... Opracowanie własne na podstawie R. House i in., Leadership, Culture and Organizations... 
charakteryzują Polaków, którzy w mniejszym stopniu odczuwają potrzebę unikania niepewności. Dystans władzy jest najwyższy w Niemczech, a na podobnym poziomie w Chinach i w Polsce. Zarówno w skali kolektywizmu instytucjonalnego, jak i kolektywizmu wewnątrzgrupowego Chińczycy osiągają najwyższe wyniki spośród wymienionych trzech państw. Jeśli chodzi o skalę asertywności niemiecka kultura osiąga wysokie wyniki, a polska, podobnie jak chińska, charakteryzuje się umiarkowaną asertywnością obywateli. W wymiarze egalitaryzm ptci Polska wypada najwyżej, czyli mocniej charakteryzuje się równym traktowaniem kobiet i mężczyzn niż Chiny czy Niemcy. Chińczycy charakteryzują się najwyższą spośród trzech państw orientacją humanistyczną, Polska średnią, natomiast Niemcy są w rankingu najniżej.

Chiny są skomplikowanym rynkiem dla zachodnich kontrahentów, różnice kulturowe w biznesie zaś podnoszą poprzeczkę trudności ${ }^{64}$. Skuteczna działalność na tamtym rynku wymaga od menedżerów umiejętności szybkiego dostosowania produktu i marki do obowiązujących w kraju wymogów dotyczących prowadzenia interesów biznesowych. Przeprowadzona analiza różnic w zarządzaniu międzykulturowym miała na celu określenie, jakiego typu praktyki biznesowe mogą się przyczynić do zwiększenia efektywności we współpracy z Chińczykami. Efektywność była rozumiana jako skuteczne rozwiązanie bieżących problemów we współpracy $^{65}$. W sytuacji kontaktu międzykulturowego, gdy spotykają się przedsiębiorcy z różnych kultur, eksporterzy i importerzy, stanowi to niezwykłe wyzwanie. Nowicjusz, kulturowy outsider, jakim jest biznesmen w pracy międzynarodowej, ze szczątkową wiedzą na temat lokalnych wartości i aktualnych praktyk, nie jest w stanie odpowiednio zareagować na nieznane sobie sposoby zachowania lub może reagować na nie tak, jakby zareagował w swojej kulturze, co nieuchronnie prowadzi do kulturowego faux-pas ${ }^{66}$. Poznanie różnic kulturowych może się odbyć na przykład poprzez treningi i warsztaty kulturowe przed przyjazdem na negocjacje biznesowe czy szkolenia w trakcie pobytu w Chinach. Bez właściwego zrozumienia norm funkcjonowania menedżerowie tam oddelegowani do pracy mogą popełniać błędy często dyskwalifikujące ich jako ekspertów z „Zachodu”, którym stawiane są wysokie wymagania. Działające w międzynarodowym biznesie firmy ponoszą straty finansowe wynikające z nieumiejętności rozwiązywania konfliktów międzykulturowych wśród pracowników. To duże ryzyko, gdyż skala rynku chińskiego jest

${ }^{64}$ Wei Wu, Is China Making Life Difficult For Foreign Companies?, przekł. własny, „South China Morning Post", 2 maja 2016, http://www.scmp.com/news/china/diplomacy-defence/article/1940397/ china-making-life-difficult-foreign-companies [dostęp 6 czerwca 2017].

${ }_{65}$ M. Budzanowska-Drzewiecka i in., Różnice..., s. 28.

${ }^{66}$ P. Boski, Kulturowe... 
coraz większa, szczególnie dlatego, że dzięki rosnącej branży e-commerce można dotrzeć do chińskiego klienta w najdalszych regionach Chin ${ }^{67}$.

\section{Summary \\ Effective cooperation with the Chinese from the cross-cultural business psychology perspective}

In recent years more Chinese executives and entrepreneurs took their business global. At the same time the challenge of China market entry has become an increasingly important issue also for the Europeans, including Poles. However when people with different cultural background encounter various tensions may arise imposing the quality of business relations. The article analyses a number of cross-cultural dimension as they have become an essential factor for understanding economic and business environments. Examples of miscommunication and failure in understanding of culture specific behaviors in the work setting between Chinese and European counterparts are discussed. The author argues that developing intercultural sensitivity is a crucial factor for fruitful communication and successful conflict resolution. The article analyzes cooperation with the Chinese from the cross-cultural psychology perspective.

${ }^{67}$ Frank Lavin w magazynie „Forbes” zajmuje się analizą rynku e-commerce w Chinach i śledzi aktualne wydarzenia związane z jego rozwojem, np. w artykule 4 Factors that Are Driving China's Consumer Surge, https://www.forbes.com/sites/franklavin/2016/12/06/4-factors-that-are-driving-chinas-consumer-surge/\#109bd50937e7 [dostęp 25 maja 2017]. 


\section{Bibliografia}

1. Airbnb Makes China Push with Local Name Change, „Financial Times”, https://www.ft.com/content/1e5bacc2-0e98-11e7-b030-768954394623.

2. Airbnb's New Chinese Name Panned by Netizens, http://shanghaiist.com/ 2017/03/22/airbnb-becomes-aibiying.php.

3. Bond M.H., Beyond Chinese Face, Oxford University Press, Hong Kong 1991.

4. Boski P., Kulturowe ramy zachowań społecznych. Podręcznik psychologii międzykulturowej, Warszawa 2009.

5. Brew F.P., Cairns D.R., Does Culture or Situational Constraints Determine Choice of Direct or Indirect Styles of Intercultural Workplace Conflicts?, „International Journal of Intercultural Relations" 2004, nr 28.

6. Budzanowska-Drzewiecka M., Marcinkowski A.S., Motyl-Adamczyk A., Różnice kulturowe w komunikacji biznesowej, Kraków 2016.

7. China Digital Land-scape Transformation, https://www.youtube.com/ watch? $=$ wjRySkvEN9w.

8. China's Post-90s Workers: The Job-Hopping Generation, http://www.whatsonweibo.com/chinas-post-1990s-job-hopping-generation/.

9. Fan Ying, A Classification of Chinese Culture, „Cross Cultural Management” 2000, nr 7(2).

10. Fernandez J.A., Underwood L., China CEO Voices of Experience from $20 \mathrm{In}$ ternational Business Leaders, Singapore 2006.

11. Gallo F.T., Business Leadership in China. How to Blend Best Western Practices with Chinese Wisdom, Singapore 2008.

12. Ge Gao, Ting-Toomey S., Communicating Effectively with the Chinese, Thousand Oaks CA 1998.

13. Gesteland R.R., Różnice kulturowe a zachowania w biznesie. Marketing negocjacje i zarządzanie $w$ różnych kulturach, przekł. H. Malarecka-Simbierowicz, Warszawa 2000.

14. Gold T., Guthrie D., Wank D., Social Connections in China-Institutions, Culture and the Changing Nature of Guanxi, Cambridge 2002.

15. Hall E.T., Beyond Culture, New York 1976.

16. Haour G., von Zedtwitz M., Created in China. How China is Becoming a Global Innovator, London 2016.

17. Hofstede G., Culture's Consequences. International Differences in Work Related Values, Beverly Hills 1980.

18. Hofstede G., Kultury i organizacje: zaprogramowanie umystu, przekł. M. Durska, Warszawa 2000, 2007. 
19. Holtgraves T.M., Styles of Language Use. Individual and Cultural Variability in Conversational Indirectness, „Journal of Personality and Social Psychology" 1997, nr 73.

20. House R., Hanges P.J., Javidan M., Dorfman P.W., Gupta V., Leadership, Culture and Organizations. The GLOBE Study of 62 Societies, Thousand Oaks CA 2004.

21. Kirkbride P.S., Tang S.F., Westwood R.I., Chinese Conflict Preferences and Negotiating Behavior. Cultural and Psychological Influences, „Organization Studies" 1991, nr 12 (3).

22. Koetse M., China's Post-90s Workers: The Job-Hopping Generation, wrzesień 2016, http://www.whatsonweibo.com/chinas-post-1990s-jo-b-hopping-generation/.

23. Langenberg E.A., Guanxi and Business Strategy Theory and Implications for Multinational Companies in China, Springer, Berlin 2007.

24. Lavin F., 4 Factors that Are Driving China's Consumer Surge, https://www. forbes.com/sites/franklavin/2016/12/06/4-factors-that-are-driving-chinas-consumer-surge/\#109bd50937e7.

25. Linka J., Rola twarzy w chińskim marketingu relacji - opinie polskich menadżerów pracujacych w Chinach, [w:] G. Rosa, A. Smalec, Marketing przyszłości. Trendy. Strategie. Instrumenty. Zachowania nabywców wczoraj, dziś i jutro, „Ekonomiczne Problemy Usług” 2010, nr 54.

26. Mazurowska K., Boski P., Czynniki istotne w procesie rozwiazywania konfliktu $w$ międzykulturowym środowisku pracy. Triangulacja w interpretacji danych, „Psychologia Społeczna” 2014, t. 9, nr 1 (28).

27. Mazurowska K., Kulturowe i osobowościowe czynniki warunkujące harmonijne lub konfliktowe zachowania organizacyjne. Chińczycy i Europejczycy w międzykulturowym środowisku pracy, praca doktorska, Szkoła Wyższa Psychologii Społecznej, Warszawa 2011.

28. Pingping Fu, Rongxian Wu, Yongkang Yang, Yun Je, Chinese Culture and Leadership, [w:] J.S. Chhokar, F.C. Brodbeck, R.J. House, Culture and Leadership Across the World the GLOBE Book of In-Depth Studies of 25 Societies, 2012.

29. Pye L.W., Chinese Commercial Negotiating Style, Santa Monica 1982.

30. Pyffel R., Biznes w Chinach - jak uniknąć problemów, Warszawa 2013.

31. Rein S., The End of Copycat China. The Rise of Creativity, Innovation and Individualism in Asia, Hoboken, New Jersey 2014.

32. Schwartz S.H., Universals in the Content and Structure of Values. Theoretical Advances and Empirical Tests in 20 Countries, „Advances in Experimental and Social Psychology" 1992, nr 25. 
33. Si Qin Peng, Guanxi - Management and Legal Approaches to Establish and Enhance Interpersonal Trust, „Journal of Psychology in Chinese Societies” 2001, nr 2 (1).

34. Trompenaars F., Hampden-Turner Ch., Siedem wymiarów kultury. Znaczenie różnic kulturowych $w$ działalności gospodarczej, przekł. B. Nawrot, Kraków 2002.

35. Uichol Kim, Kuo-shu Yang, Kwang-Kuo Hwang (red.), Indigenous and Cultural Psychology. Understanding People in Context, Berlin 2006.

36. Verner I., Beamer L.(red.), Intercultural Communication in the Global Workplace, New York 2011.

37. Wei Wu, Is China Making Life Difficult For Foreign Companies?, „South China Morning Post", 2 maja 2016, http://www.scmp.com/news/china/diplomacy-defence/article/1940397/ china-making-life-difficult-foreign-companies.

38. Yan Wang, Wptyw modernizacji Chin na funkcjonowanie guanxi w chińskim społeczeństwie, „Azja-Pacyfik” 2015, t. 18.

39. YinLun So, Walker A., Explaining Guanxi. Chinese Business Network, New York 2013.

40. Yip G.S., Kern B., China's Next Strategic Advantage. From Imitation to Innovation, London 2016.

41. Zajdler E. (red.), Zrozumieć Chińczyków. Kulturowe kody społeczności chińskich, Warszawa 2011.

42. Zhaopin: Nearly 80\% of China White Collars Trying to Switch Jobs, http:// zhaopin.investorroom.com/2017-02-28-Zhaopin-Nearly-80-of-China-White-Collars-Trying-to-Switch-Jobs.

43. Zhi Xue Zhang, Jianjun Zhang (red.), Understanding Chinese Firms from Multiple Perspectives, Berlin-Peking 2014. 